\title{
From the intestinal mucosal barrier to the enteric neuromuscular compartment: An integrated overview on the morphological changes in Parkinson's disease
}

\author{
Carolina Pellegrini, ${ }^{1}$ Vanessa D'Antongiovanni, ${ }^{2}$ Chiara Ippolito, ${ }^{1}$ Cristina Segnani, ${ }^{1}$ Luca Antonioli, ${ }^{2}$ \\ Matteo Fornai, ${ }^{2}$ Nunzia Bernardini ${ }^{1,3}$ \\ ${ }^{1}$ Department of Clinical and Experimental Medicine, Unit of Histology, University of Pisa \\ ${ }^{2}$ Department of Clinical and Experimental Medicine, Unit of Pharmacology and Pharmacovigilance, University of Pisa \\ ${ }^{3}$ Interdepartmental Research Center "Nutraceuticals and Food for Health", University of Pisa, Italy
}

\begin{abstract}
Gastrointestinal dysfunctions represent the most common non-motor symptoms in Parkinson's disease (PD). Of note, changes in gut microbiota, impairments of intestinal epithelial barrier (IEB), bowel inflammation and neuroplastic rearrangements of the enteric nervous system (ENS) could be involved in the pathophysiology of the intestinal disturbances in PD. In this context, although several review articles have pooled together evidence on the alterations of enteric bacteria-neuro-immune network in PD, a revision of the literature on the specific morphological changes occurring in the intestinal mucosal barrier, the ENS and enteric muscular layers in PD, is lacking. The present review provides a complete appraisal of the available knowledge on the morphological alterations of intestinal mucosal barrier, with particular focus on IEB, ENS and enteric muscular layers in PD. In particular, our intent was to critically discuss whether, based on evidence from translational studies and preclinical models, morphological changes in the intestinal barrier and enteric neuromuscular compartment contribute to the pathophysiology of intestinal dysfunctions occurring in PD.
\end{abstract}

Key words: Intestinal epithelial barrier, enteric nervous system, neuromuscular compartment, patients, animal models, Parkinson's disease.

Correspondence: Prof. Nunzia Bernardini, Unit of Histology and Medical Embryology, Department of Clinical and Experimental Medicine, University of Pisa, Via Roma 55, 56126 Pisa, Italy.

Tel. +39.050.2218621. E-mail: nunzia.bernardini@med.unipi.it

Contributions: CP, VDA, manuscript drafting: CI, CS figures and tables implementation; LA, MF, NB, manuscript revision. All the authors made a substantive intellectual contribution, have read and approved the final version of the manuscript and agreed to be accountable for all aspects of the work.

Conflict of interest: The authors declare no conflict of interest, and all authors confirm accuracy. 


\section{Introduction}

Patients with Parkinson's disease (PD) can experience gastrointestinal dysfunctions, ${ }^{1,2}$ including dysphagia, infrequent bowel movements and constipation, which often precede the onset of typical motor symptoms of the disease. ${ }^{3,4}$ Of note, gut dysbiosis, alterations of the intestinal mucosal barrier, bowel inflammation, neuroplastic changes in the enteric nervous system (ENS) and rearrangements of the enteric muscular compartment have been proposed to be involved in the pathophysiology of intestinal symptoms in PD. ${ }^{1,2,5}$ In this context, a number of review articles has provided an in-depth overview about the changes in gut microbiota, impairments of intestinal epithelial barrier (IEB), the occurrence of intestinal immune/inflammatory responses and alterations of the enteric neuromuscular compartment in PD. ${ }^{1,6,7}$ However, a review article providing an integrated appraisal of the specific morphological changes occurring in the intestinal mucosal barrier, ENS and enteric muscular layers in PD, is lacking.

Based on the above background, the present review has been conceived to provide a complete overview of the available knowledge on the morphological alterations in the intestinal mucosal barrier, with particular interest in IEB, ENS and enteric muscular layers in PD. In particular, our intent was to critically discuss, based on current pre-clinical and human evidence, whether changes in the IEB and enteric neuromuscular system contribute to the pathophysiology of intestinal disturbances associated with PD. This body of knowledge might help a better understanding of the mechanisms underlying intestinal dysfunctions in PD and pave the way to the identification of novel targets for the development of innovative pharmacological approaches for the therapeutic management of such disturbances.

\section{Morphology and physiology of the intestinal mucosal barrier and neuromuscular compartment}

The IEB, ENS and enteric muscular compartment act as a teamwork in the regulating of several gut functions, including nutrient absorption, immunoglobulin secretion and motility. ${ }^{8-10}$

The IEB represents an epithelial cell monolayer, consisting of enterocytes, goblet, enteroendocrine and Paneth cells, organized in protrusions (villi) in the small intestine and tubular glands in the colon, both ending with invaginations (crypts), which contain the stem cell niches (Figure 1). The IEB acts as physical barrier between luminal content and the underlying immune-neuro-muscular compartments and it regulates absorptive/secretory functions and intestinal permeability. ${ }^{10,11}$ Goblet cells $\left(\mathrm{MUC2}^{+}\right.$) secrete mucins, which, forming hydrated gel layer, contribute to prevent the infiltration of pathogen agents into intestinal mucosa. ${ }^{11,12}$ The production of mucus is controlled by several factors, including transmembrane 16A/Anoctamin 1 (TMEM16A/ANO1). ${ }^{13,14}$ Enterocytes, besides regulating absorption/secretory functions, release intestinal hormones or peptides ${ }^{15}$ and participate in the induction of oral tolerance to food and microbial antigens. ${ }^{16}$ Paneth cells, located in the small intestinal crypt niche, secrete antimicrobial peptides that contribute both to maintain eubiosis and safeguard neighboring stem cells (Figure 1) ${ }^{17}$ The subsets of intestinal epithelial cells are bound together by junctional complexes, including tight junctions (TJs), adherent and gap junctions and desmosomes. ${ }^{18} \mathrm{TJ}$, the most apical junctions, include claudins, occludins, tricellulin and zonula occludens ( $\mathrm{ZO}$ ) proteins. Occludin and ZO-1 proteins are mainly involved in the modulation of paracellular permeability, while claudins are the main structural determinants of the TJs. ${ }^{19,20}$ Adherent junctions share a common structural organization with the junctional complex maintaining the mechanical integrity of barrier. ${ }^{21}$ Gap junctions form channels between adjacent cells linking together their cytoplasms while desmosomes are located along the lateral membranes beneath adherent junctions. ${ }^{20}$

Of note, a sub-epithelial stromal cell network, including fibroblasts and myofibroblasts, contributes to maintain IEB integrity, mucosal growth and development, and neuromodulation of intestinal motility. ${ }^{22,23}$ Sub-epithelial fibroblasts are nonhematopoietic $\left(\mathrm{CD}^{-} 5^{-}\right)$, non-endothelial (CD31-) cells that express the surface marker cluster differentiation 90 (CD90), plateletderived growth factor receptor alpha (PDGFR $\alpha$ ) and vimentin but not $\alpha$-smooth muscle actin ( $\alpha$-SMA) and desmin. . $^{22,24,25}$ Sub-epithelial fibroblasts are located in the upper part of the crypts in proximity of basolateral surface of epithelial cells (Figure 1). Myofibroblasts, regarded as fibroblasts endowed with smooth muscle cells properties, are contractile cells located under the epithelial layer around the small intestinal and colonic crypts (Figure 1); ${ }^{26}$ they are $\alpha$-SMA ${ }^{-}, \mathrm{CD} 90^{-}$and vimentin-positive while they do not express desmin and myosin smooth muscle cell markers. ${ }^{22,26}$

The enteric neuromuscular compartment, including ENS (enteric neurons and glia), interstitial cells of Cajal (ICCs) and smooth muscle cells, besides modulating well-known repertoire of physiological functions, including secretive/absorptive and motor functions, contributes also actively to preserving IEB integrity (Figure 1). ${ }^{27}$ Indeed, the ENS arranged into the submucosal plexus (or Meissner's plexus), located in the submucosa, and the myenteric plexus (or Auerbach's plexus), located between the circular and longitudinal muscle layer, ${ }^{27}$ besides contributing to the motor control of smooth muscles, contributes to the maintenance of IEB integrity and permeability. ${ }^{28}$ For instance, neurotransmitters released from enteric neurons $\left(\mathrm{HuC} / \mathrm{D}^{+}\right.$and $\left.\mathrm{PGP} 9.5^{+}\right)$, including vasoactive intestinal peptide (VIP), acetylcholine, substance $\mathrm{P}$ (SP), calcitonin gene-related peptide (CGRP) and 5-hydroxytriptamine (5-HT), influence gut motility as well as modulate intestinal barrier permeability and integrity. ${ }^{29}$ There are also enteric dopaminergic neurons (dopamine transporter, $\mathrm{DAT}^{+}$and tyrosine hydroxylase, $\mathrm{TH}^{+}$). However, the enteric dopaminergic pathway is primarily involved in the inhibitory regulation of upper GI tract motility, while exerting a slight control in the lower digestive tract. ${ }^{30}$ In addition, despite studies in rodents have demonstrated that dopamine increased duodenal permeability and mucus secretion via dopamine D5 receptor subtypes, ${ }^{31,32}$ no evidence about a direct influence of dopamine released from intrinsic enteric neurons on intestinal epithelial barrier is available.

With regard for VIP and acetylcholine, it has been observed that they can modulate permeability in response to different stimuli and preserve barrier integrity. ${ }^{29}$ In addition, cholinergic neurons, axonal reflexes from sensory afferent neurons releasing SP and CGRP can directly promote intestinal epithelial cell differentiation and proliferation, while 5-HT has been found to indirectly contribute to epithelial cell renewal through the recruitment of cholinergic pathways. ${ }^{33,34}$ Likewise, enteric glial cells [EGCs, expressing glial fibrillary acidic protein (GFAP), S100 calcium-binding protein $\mathrm{B}(\mathrm{S} 100 \beta)$ and sex determining region $\mathrm{Y}$ box-containing gene 10 (Sox 10)] located in proximity to epithelial cells, submucosal (or Meissner's) and myenteric (or Auerbach's) plexi contribute to maintain barrier integrity, secretory functions and regulation of bowel motility, respectively (Figure 1). ${ }^{35-38}$ In particular, these cells can release specific mediators (e.g., glial cell-derived neurotrophic factor [GDNF] and 15-deoxy-(12,14)-prostaglandin J2 [15dPGJ2] glial factor), that, in turn, contribute to preserve epithelial barrier integrity. ${ }^{35}$ For instance, glial cell-derived GDNF can promote the proliferation of stem cells or cells in the crypt niche such as Paneth 
cells ${ }^{36,37}$

ICCs are stellate cells, expressing receptor tyrosine kinase (cKIT) and TMEM16A/ANO1, bound together by gap junctions (Figure 1). ${ }^{39}$ Briefly, ICCs, with slight morphological differences, are located along the submucosal surface of colonic circular muscle bundles (ICCs-SM), in the myenteric plexus (ICCs-MY) and intramuscularly (ICCs-IM) in the esophagus, stomach, and colon. Of note, ICC are considered pacemaker cells of bowel motility, by generating spontaneous and rhythmic electrical activity as well as bridging cells between enteric neurons and smooth muscle cells. ${ }^{27}$

The enteric muscular compartment is arranged in a circular muscle layer, oriented along the transversal axis, that generates forward transit and the longitudinal muscle layer, where smooth muscle cells are oriented along the longitudinal axis, that contribute to the maintenance of intestinal muscle tone, to shorten the length and support the propulsion. ${ }^{27}$

Overall, IEB and enteric neuromuscular compartment coordi- nate digestive adsorptive/secretory and motor functions. In this respect, intestinal immune system contributes to orchestrate both IEB and enteric neuromuscular compartment functions. However, in this section, we have focused attention on the morphology and physiology of intestinal barrier, ENS and enteric muscular layers in order to better understand how changes in this neuro-muscularbarrier network can contribute to intestinal dysfunctions in PD.

\section{Pathological remodeling of the intestinal mucosal barrier and enteric neuromuscular compartment in PD}

\section{Intestinal mucosal barrier}

Clinical evidence displays that PD patients are characterized by morphological alterations of IEB. Clairembault et al. observed
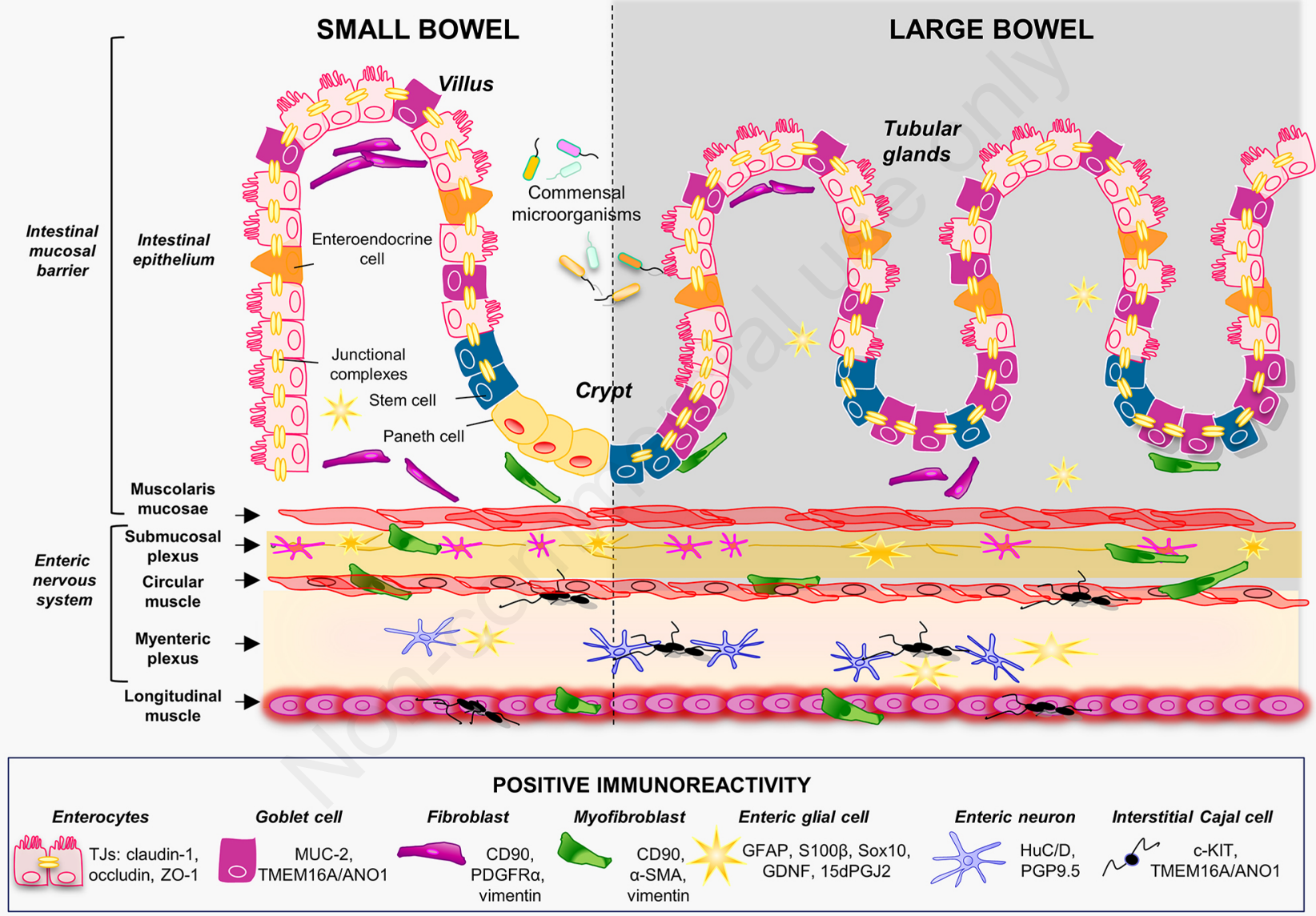

Figure 1. Diagram showing the morphology of intestinal mucosal barrier, enteric nervous system (ENS) and neuromuscular compartment in small and large bowel. The intestinal epithelial barrier (IEB) represents an epithelial cell monolayer, consisting of enterocytes, goblet cells, enteroendocrine and Paneth cells, organized in protrusions (villi) in the small intestine and tubular glands in the colon. At the bottom of the crypts, there is a small number of stem cells. The subsets of epithelial cells are bound together by junctional complexes, including TJs, gap and adherent junctions and desmosomes. The lamina propria, besides containing a number of innate and adaptive immune cells, is characterized by an intricate network of fibroblasts localized in the upper part of the crypts in proximity of basolateral surface of epithelial cells. Myofibroblasts, regarded as fibroblasts endowed with smooth muscle cells properties, are contractile cells located under the epithelial layer around the small intestinal and colonic crypts and in the tunica muscularis. Among the cellular components of ENS, EGCs, ICC and smooth muscle cells play a pivotal role in the regulation of gut homeostasis. EGCs are associated with both submucosal and myenteric neurons and are located also in proximity to epithelial cells. ICCs are present in the intramuscular space. The muscular compartment is arranged in a circular muscle layer, oriented along the transversal axis, and the longitudinal muscle layer, where fibers are oriented along the longitudinal axis. Abbreviations: $\alpha-S M A, \alpha$-smooth muscle actin; Anoctamin 1, TMEM16A/ANO1; CD90, Cluster Differentiation 90; c-KIT, receptor tyrosine kinase; EGCs, enteric glial cells; ENS, enteric nervous system; GDNF, glial cell-derived neurotrophic factor; GFAP, glial fibrillary acidic protein; ICC, interstitial cells of Cajal; IEB, intestinal epithelial barrier; MUC-2: mucin 2; PDGFR $\alpha$, platelet-derived growth factor receptor alpha; $S 100 \beta$, S100 calcium-binding protein B; Sox-10, sex determining region Y box-containing gene 10; TJs, tight junctions; ZO-1, zonulin-1. 
an abnormal subcellular distribution of colonic occludin and ZO-1 of PD patients at different stages of the disease. ${ }^{40}$ In particular, occludin and ZO-1 morphology was disrupted and irregularly distributed in PD patients, as compared with the normal and typical reticular pattern of TJs observed in control subjects (Table 1). In addition, an increased occludin immunopositivity were detected in the cytoplasm of colonic enterocytes from PD patients, while it was mostly located in the colonic TJs in control group, suggesting a protein internalization in PD patients (Table 1). The authors also detected a TJs disorganization in levodopa-untreated PD patients, suggesting that alterations of TJ morphology were not associated with chronic levodopa treatment. The altered subcellular distribution and expression of TJs could contribute to the impairments of intestinal barrier integrity and permeability with consequent translocation of microbial pathogens into the mucosa and occurrence of immune/inflammatory responses that, in turn, could further contribute to bowel dysfunctions. ${ }^{1,40,41}$ Supporting this hypothesis, in a recent paper, Perez-Pardo et al. showed that PD patients were characterized by an increase in sucralose excretion, regarded as a marker of increased intestinal permeability, along with a decrease in immunopositivity of ZO-1 in colon biopsies from PD patients (Table 1). ${ }^{2}$ In addition, they documented in the same cohort of PD patients gut dysbiosis, enhanced markers of microbial translocation along with an increase in pro-inflammatory gene profiles and TLR $-4^{+}, \mathrm{CD}^{+} \mathrm{T}$ cells in colonic biopsies. ${ }^{2}$

Of interest, the implementation of animal models of PD has allowed to better clarify the correlation among impairments of intestinal barrier and bowel dysfunctions in PD. In particular, several studies have shown IEB impairments in different experimental models of PD (Table 1). Kelly et al. showed that lipopolysaccharide (LPS)-induced PD mice displayed an increased intestinal permeability, ${ }^{42}$ while a decreased expression of colonic ZO-1 and claudin-1 was detected in mice with rotenone and 6-hydroxydopamine (6-OHDA)-induced PD, respectively. ${ }^{2,43}$ Pellegrini and colleagues also reported that 6-hydroxydopamine (6-OHDA) animals were characterized by an increase in mucin expression in colonic epithelial cells. ${ }^{43}$ In particular, the histological analysis revealed the concomitance of a mucous metaplasia of colonic epithelium, an increased number of goblet cells, containing metachromatic acid mucin, and a fast epithelial turnover in colonic crypts, suggesting a renewal and differentiation of epithelial cells into goblet phenotype to reinforce the intestinal barrier (Table 1). ${ }^{43}$ In addition, 6-OHDA rats displayed a decrease in colonic expression of TMEM16A/ANO1, mucosal hydration along with a decrease in fecal water content that could contribute to delay in colonic transit (Table 1). ${ }^{43-45}$ Of note, 6-OHDA rats displayed a marked collagen deposition along with an increase in vimentinpositive fibroblast-like cells some of which resulted proliferating cellular nuclear antigen (PCNA)-positive as well as several epithelial cells of the crypts, while $\alpha$-SMA-positive cells resulted decreased. ${ }^{43}$ These findings suggest that central nigrostriatal denervation is associated with gut fibrotic remodelling that could contribute to alterations both of intestinal permeability and motor disturbances. ${ }^{43}$

\section{Enteric nervous system}

Several studies have provided evidence about morphological changes of ENS as well as enteric $\alpha$-synuclein accumulation (ENS Lewy pathology) in PD patients that could contribute to the alterations of bowel motility. In a previous study, Singaram et al., 1995 showed that, in the submucosal plexus, the number of tyrosine hydroxylase (TH)- and dopamine-positive neurons did not differ between PD and control patients, while the number of dopamine, but not $\mathrm{TH}$, positive neurons were decreased in the myenteric plexus (Table 1). ${ }^{46}$ Others reported no changes in the density of VIP, SP and neuropeptide Y, NO or dopamine-positive neurons in colonic biopsies from PD patients ${ }^{47,48}$. In addition, there is a lack of data about changes in the density of myenteric cholinergic and nitrergic neurons in PD. In this respect, further morphological studies are needed to better characterize enteric neuroplastic remodelling associated with $\mathrm{PD}$.

Of note, a recent study showed an activation of EGCs, in terms of increased mRNA expression of GFAP and Sox-10, in colonic biopsies from PD patients. ${ }^{49}$ These patterns correlated with enhanced mRNA pro-inflammatory cytokines levels. However, no clinical evidence about changes in morphology and distribution of

Table 1. Summary of morphological changes in intestinal mucosal barrier and enteric neuromuscular compartment in PD.

\begin{tabular}{|c|c|c|c|c|}
\hline \multicolumn{2}{|c|}{ Intestinal mucosal barrier } & Enteric nervous system & Enteric muscular compartment & Ref. \\
\hline \multicolumn{5}{|c|}{ Clinical studies } \\
\hline \multicolumn{2}{|c|}{$\begin{array}{l}\checkmark \quad \downarrow \text { occludin and ZO-1 expression } \\
\checkmark \text { altered cellular distribution of occludin and ZO-1 } \\
\checkmark \uparrow \text { occludin in the cytoplasm of enterocytes } \\
\checkmark \uparrow \text { sucralose excretion }\end{array}$} & $\begin{array}{l}\checkmark \text { submucosal plexus: no differences between TH- } \\
\text { and DA-positive neurons } \\
\checkmark \uparrow \alpha \text {-synuclein inclusions } \\
\checkmark \text { myenteric plexus: } \downarrow \text { DA-positive neurons; no } \\
\text { difference in TH-positive neurons }\end{array}$ & $\checkmark$ n.a. & $\begin{array}{l}1,2 \\
40,41 \\
46-49 \\
50-53\end{array}$ \\
\hline \multicolumn{5}{|c|}{ Experimental models } \\
\hline $\begin{array}{l}\text { Rotenone-induced central } \\
\text { dopaminergic } \\
\text { neurodegeneration }\end{array}$ & $\checkmark \quad \downarrow$ ZO-1 expression & $\begin{array}{ll}\checkmark & \uparrow \text { VIP-ergic and dopaminergic neurons } \\
\checkmark & \downarrow \text { nitrergic neurons }\end{array}$ & $\checkmark$ n.a. & $\begin{array}{l}2 \\
57\end{array}$ \\
\hline $\begin{array}{l}\text { LPS-induced central } \\
\text { neuroinflammation/neurodeg } \\
\text { eneration }\end{array}$ & $\checkmark \uparrow$ intestinal permeability & $\checkmark$ n.a. & $\checkmark$ n.a. & 42 \\
\hline $\begin{array}{l}\text { 6-OHDA-induced central } \\
\text { nigrostriatal denervation }\end{array}$ & $\begin{array}{ll}\checkmark & \downarrow \text { claudin-1 expression } \\
\checkmark & \uparrow \text { mucin expression } \\
\checkmark & \uparrow \text { number of goblet cells } \\
\checkmark & \text { mucous metaplasia } \\
\checkmark & \downarrow \text { TMEM16A/ANO1 } \\
\checkmark & \uparrow \text { vimentin-positive fibroblast-like cells } \\
\checkmark & \downarrow \alpha \text {-SMA-positive cells }\end{array}$ & $\begin{array}{l}\checkmark \uparrow \text { VIP-ergic and dopaminergic neurons } \\
\checkmark \downarrow \text { nitrergic neurons } \\
\checkmark \downarrow \text { ChAT } \\
\checkmark \uparrow \text { SP-immunoreactive neurons } \\
\checkmark \uparrow \text { GFAP and S100 } \beta\end{array}$ & $\begin{array}{ll}\checkmark & \uparrow \text { NK }_{1} \text { receptors } \\
\checkmark & \downarrow \alpha \text {-SMA and desmin-positive smooth } \\
& \text { muscle cells } \\
\checkmark & \uparrow \text { vimentin- and } \alpha \text {-SMA-positive } \\
& \text { fibroblast/myofibroblast-like cell } \\
\checkmark & \uparrow \text { collagen deposition } \\
\checkmark & \downarrow \text { ICC density }\end{array}$ & $\begin{array}{l}43-45 \\
56,58\end{array}$ \\
\hline $\begin{array}{l}\text { MPTP-induced central } \\
\text { dopaminergic } \\
\text { neurodegeneration }\end{array}$ & $\checkmark$ n.a. & $\checkmark \downarrow$ dopaminergic neurons & $\checkmark$ n.a. & 54,55 \\
\hline
\end{tabular}


these cells are available.

With regard for the distribution and localization of Lewy pathology in GI tract from PD patients, several studies have documented that the presence of $\alpha$-synuclein inclusions in intestinal myenteric and submucosal neurons occur between $50 \%$ and $100 \%$ of PD patients. ${ }^{50}$ In particular, the $\alpha$-synuclein accumulation in duodenal, ileal and colonic neurons has been documented at all stages of the disease, suggesting that their accumulation could represent a biomarker of PD. ${ }^{51-53}$ However, clear relationships between colonic $\alpha$-synuclein accumulation and neuroplastic changes of ENS during PD have not been established.

Of interest, morphological studies in animal models of PD have shown rearrangements of the enteric dopaminergic, nitrergic, VIP-ergic, cholinergic and tachykininergic neurons ${ }^{45,54-58}$ In particular, an increase in enteric VIP-ergic and dopaminergic neurons along a decrease in nitrergic neurons were detected in animals with PD induced by intranigral 6-OHDA injection and peripheral administration rotenone. ${ }^{56,57}$ Conversely, Anderson et al. displayed a loss of dopaminergic neurons associated with altered colonic motility in MPTP (1-methyl 4-phenyl 1,2,3,6-tetrahydropyridine)treated mice. ${ }^{54}$ In addition, a decrease in ChAT immunopositivity along with an increase in SP-immunoreactive neurons were observed in colonic tissues from PD animals (Table 1). ${ }^{45,58}$ These findings suggest that PD is associated with a remodelling of enteric excitatory and inhibitory neuronal coding that could contribute to the alterations of gut motility.

Of note, morphological investigations have shown an increased density and activation of enteric glia both in colonic myenteric ganglia and in mucosal layer from 6-OHDA animals. ${ }^{43,45,59}$ In particular, 6-OHDA animals displayed a significant increase in glial GFAP immunopositivity cells in colonic myenteric plexus. ${ }^{45}$ Besides in the myenteric ganglia, a significant increase in glial S100 $\beta$-positive cells were detected in the colonic tunica mucosa of 6-OHDA rats, suggesting that nigrostriatal neurodegeneration leads to a rearrangement of enteric glial network that could contribute both to the colonic dysmotility and mucosal barrier impairment (Table 1). ${ }^{43}$

\section{Enteric muscular compartment}

Clinical evidence about morphological changes in enteric muscular compartment in PD patients are lacking. Only two pre-clinical studies in 6-OHDA rats have shown alterations of intestinal muscular layers. In a first study, Pellegrini et al. showed an increase in $\mathrm{NK}_{1}$ receptors in colonic longitudinal muscle cells from 6-OHDA animals that could contribute to the altered colonic tachykininergic neurotransmission (Table 1). ${ }^{58}$ In the second paper, a rearrangement of smooth muscle cells in colonic tissues from 6OHDA rats has been reported. In particular, the authors showed that the colonic smooth muscle cell phenotype ( $\alpha$-SMApositive/desmin-positive/vimentin-negative) was replaced by smooth muscle cells with decreased $\alpha$-SMA and desmin immunoreactivity (Table 1). ${ }^{43}$ In addition, 6-OHDA animals displayed an increase in vimentin and $\alpha$-SMA-positive fibroblast/myofibroblasts-like cells along with an increased collagen deposition in the colonic tunica muscularis, suggesting that central nigrostriatal denervation is associated with a cellular fibrotic switch in the tunica muscularis that could contribute to bowel motor dysfunctions (Table 1). ${ }^{43}$

Besides smooth muscle cell switch towards fibrotic phenotype, 6-OHDA animals were also characterized by a decrease in the density of TMEM/ANO1-positive ICCs along myenteric ridge with a loss of their extensions in circular layers that could further contribute to the development of colonic dysmotility (Table 1). ${ }^{43}$

\section{Conclusions and future perspectives}

Current evidence points out that morphological alterations of IEB, ENS and intestinal muscular compartment in PD could contribute to intestinal dysfunctions. Indeed, both human and pre-clinical studies show that PD is associated with changes in the expression of distribution of TJs, altered mucus production, rearrangement of enteric neuronal coding, gut wall fibrotic remodelling and alterations of enteric muscular cells. However, the mechanisms underlying the interplays between IEB and enteric neuromuscular compartment as well as their role in the pathophysiology of bowel disturbances in PD remain to be clarified. In this respect, gut dysbiosis and the occurrence of enteric immune/inflammatory responses could play a crucial role. Indeed, human and pre-clinical studies have shown concomitance of changes in gut microbiota, impairments of IEB, enteric inflammation and rearrangement of enteric neuromuscular compartment in PD.

In conclusion, based on current knowledge, some important issues need to be clarified. For instance, what are the mechanisms underlying the interplay among intestinal mucosal barrier and enteric neuromuscular compartment in the onset of bowel dysfunctions associated with PD? What is the role of enteric inflammation? Can histochemical analyses of gut wall represent a useful diagnostic tool for achieving insights into intestinal symptoms in PD? To clarify these points, research efforts should be addressed to investigate the concomitance of morphofunctional alterations of intestinal mucosal barrier and enteric neuromuscular compartment in animal models as well as in PD patients since the prodromal stages of disease. Understanding these aspects could pave the way to the validation of routine colonic biopsies for diagnosis of intestinal disturbances in PD as well as to the identification of reliable and early pharmacological strategies for their clinical management.

\section{References}

1. Pellegrini C, Antonioli L, Colucci R, Blandizzi C, Fornai M. Interplay among gut microbiota, intestinal mucosal barrier and enteric neuro-immune system: a common path to neurodegenerative diseases? Acta Neuropathol 2018;136:345-61.

2. Perez-Pardo P, Dodiya HB, Engen PA, Forsyth CB, Huschens AM, Shaikh M, et al. Role of TLR4 in the gut-brain axis in Parkinson's disease: a translational study from men to mice. Gut 2019;68:829-43.

3. Fasano A, Visanji NP, Liu LW, Lang AE, Pfeiffer RF. Gastrointestinal dysfunction in Parkinson's disease. Lancet Neurol 2015;14:625-39.

4. Pfeiffer RF. Gastrointestinal dysfunction in Parkinson's disease. Curr Treat Options Neurol 2018;20:54.

5. D'Antongiovanni V, Pellegrini C, Fornai M, Colucci R, Blandizzi C, Antonioli L, Bernardini N. et al. Intestinal epithelial barrier and neuromuscular compartment in health and disease. World J Gastroenterol 2020;26:1564-79.

6. Keshavarzian A, Green SJ, Engen PA, et al. Colonic bacterial composition in Parkinson's disease. Mov Disord 2015;30:1351-60.

7. Rutsch A, Kantsjo JB, Ronchi F. The gut-brain axis: How microbiota and host inflammasome influence brain physiology and pathology. Front Immunol 2020;11:604179.

8. Spencer NJ, Hu H. Enteric nervous system: sensory transduction, neural circuits and gastrointestinal motility. Nat Rev Gastroenterol Hepatol 2020;17:338-51.

9. Sanders KM, Koh SD, Ro S, Ward SM. Regulation of gastroin- 
testinal motility--insights from smooth muscle biology. Nat Rev Gastroenterol Hepatol 2012;9:633-45.

10. Chelakkot C, Ghim J, Ryu SH. Mechanisms regulating intestinal barrier integrity and its pathological implications. Exp Mol Med 2018;50:103.

11. Salvo Romero E, Alonso Cotoner C, Pardo Camacho C, Casado Bedmar M, Vicario M. The intestinal barrier function and its involvement in digestive disease. Rev Esp Enferm Dig 2015;107:686-96.

12. Kim YS, Ho SB. Intestinal goblet cells and mucins in health and disease: recent insights and progress. Curr Gastroenterol Rep 2010;12:319-30.

13. Pedemonte N, Galietta LJ. Structure and function of TMEM16 proteins (anoctamins). Physiol Rev 2014;94:419-59.

14. Keely S, Kelly CJ, Weissmueller T, Burgess A, Wagner BD, Robertson CE, et al. Activated fluid transport regulates bacterial-epithelial interactions and significantly shifts the murine colonic microbiome. Gut Microbes 2012;3:250-60.

15. Kong S, Zhang YH, Zhang W. Regulation of intestinal epithelial cells properties and functions by amino acids. BioMed Res Int 2018;2018:2819154.

16. Miron N, Cristea V. Enterocytes: active cells in tolerance to food and microbial antigens in the gut. Clin Exp Immunol 2012;167:405-12.

17. Clevers HC, Bevins CL. Paneth cells: maestros of the small intestinal crypts. Ann Rev Physiol 2013;75:289-311.

18. Turner JR. Intestinal mucosal barrier function in health and disease. Nat Rev Immunol 2009;9:799-809.

19. Lu Z, Ding L, Lu Q, Chen YH. Claudins in intestines: Distribution and functional significance in health and diseases. Tissue Barriers 2013;1:e24978.

20. Anderson JM, Van Itallie CM. Physiology and function of the tight junction. Cold Spring Harb Perspect Biol 2009;1:a002584.

21. Hartsock A, Nelson WJ. Adherens and tight junctions: structure, function and connections to the actin cytoskeleton. Biochim Biophys Acta 2008;1778:660-9.

22. Pinchuk IV, Mifflin RC, Saada JI, Powell DW. Intestinal mesenchymal cells. Curr Gastroenterol Rep 2010;12:310-8.

23. Powell DW, Mifflin RC, Valentich JD, Crowe SE, Saada JI, West AB. Myofibroblasts. II. Intestinal subepithelial myofibroblasts. Am J Physiol 1999;277:C183-201.

24. Kurahashi M, Nakano Y, Peri LE, Townsend JB, Ward SM, Sanders KM. A novel population of subepithelial platelet-derived growth factor receptor alpha-positive cells in the mouse and human colon. Am J Physiol Gastrointest Liver Physiol 2013;304:G823-34.

25. Higuchi Y, Kojima M, Ishii G, Aoyagi K, Sasaki H, Ochiai A. Gastrointestinal fibroblasts have specialized, diverse transcriptional phenotypes: A comprehensive gene expression analysis of human fibroblasts. PloS One 2015;10:e0129241.

26. Mifflin RC, Pinchuk IV, Saada JI, Powell DW. Intestinal myofibroblasts: targets for stem cell therapy. Am J Physiol Gastrointest Liver Physiol 2011;300:G684-96.

27. Furness JB, Callaghan BP, Rivera LR, Cho HJ. The enteric nervous system and gastrointestinal innervation: integrated local and central control. Adv Exp Med Biol 2014;817:39-71.

28. Puzan M, Hosic S, Ghio C, Koppes A. Enteric nervous system regulation of intestinal stem cell differentiation and epithelial monolayer function. Sci Rep 2018;8:6313.

29. Fornai M, van den Wijngaard RM, Antonioli L, Pellegrini C, Blandizzi C, de Jonge WJ. Neuronal regulation of intestinal immune functions in health and disease. Neurogastroenterol Motil 2018;30:e13406.

30. Longo WE, Vernava AM, 3rd. Prokinetic agents for lower gas- trointestinal motility disorders. Dis Colon Rectum 1993;36:696-708.

31. Feng XY, Zhang DN, Wang YA, Fan RF, Hong F, Zhang Y, et al. Dopamine enhances duodenal epithelial permeability via the dopamine D5 receptor in rodent. Acta Physiol (Oxf) 2017;220:113-23.

32. Li Y, Zhang Y, Zhang XL, Feng XY, Liu CZ, Zhang XN, et al. Dopamine promotes colonic mucus secretion through dopamine D5 receptor in rats. Am J Physiol Cell Physiol 2019;316:C393-403.

33. Lundgren O, Jodal M, Jansson M, Ryberg AT, Svensson L. Intestinal epithelial stem/progenitor cells are controlled by mucosal afferent nerves. PloS One 2011;6:e16295.

34. Gross ER, Gershon MD, Margolis KG, Gertsberg ZV, Li Z, Cowles RA. Neuronal serotonin regulates growth of the intestinal mucosa in mice. Gastroenterology 2012;143:408-17.

35. Neunlist M, Rolli-Derkinderen M, Latorre R, Van Landeghem L, Coron E, Derkinderen P, et al. Enteric glial cells: recent developments and future directions. Gastroenterology 2014;147:1230-7.

36. Yu YB, Li YQ. Enteric glial cells and their role in the intestinal epithelial barrier. World J Gastroenterol 2014;20:11273-80.

37. Vergnolle N, Cirillo C. Neurons and glia in the enteric nervous system and epithelial barrier function. Physiology 2018;33:269-80.

38. Delvalle NM, Fried DE, Rivera-Lopez G, Gaudette L, Gulbransen BD. Cholinergic activation of enteric glia is a physiological mechanism that contributes to the regulation of gastrointestinal motility. Am J Physiol Gastrointest Liver Physiol 2018;315:G473-83.

39. Gomez-Pinilla PJ, Gibbons SJ, Bardsley MR, Lorincz A, Pozo MJ, Pasricha PJ, et al. Anol is a selective marker of interstitial cells of Cajal in the human and mouse gastrointestinal tract. Am J Physiol Gastrointest Liver Physiol 2009;296:G1370-81.

40. Clairembault T, Leclair-Visonneau L, Coron E, Bourreille A, Le Dily S, Vavasseur F, et al. Structural alterations of the intestinal epithelial barrier in Parkinson's disease. Acta Neuropathol Commun 2015;3:12.

41. Bischoff SC, Barbara G, Buurman W, Ockhuizen T, Schulzk JD, Serino M, et al. Intestinal permeability--a new target for disease prevention and therapy. BMC Gastroenterol 2014;14:189.

42. Kelly LP, Carvey PM, Keshavarzian A, Shannon KM, Shaikh M, Bakayet RAE, al. Progression of intestinal permeability changes and alpha-synuclein expression in a mouse model of Parkinson's disease. Mov Dis 2014;29:999-1009.

43. Pellegrini C, Ippolito C, Segnani C, Dolfi A, Errede M, Virgintino D, et al. Pathological remodelling of colonic wall following dopaminergic nigrostriatal neurodegeneration. Neurobiol Dis 2020;139:104821.

44. Zhang X, Li Y, Liu C, Fan R, Wang P, Zheng L, et al. Alteration of enteric monoamines with monoamine receptors and colonic dysmotility in 6-hydroxydopamine-induced Parkinson's disease rats. Transl Res 2015;166:152-62.

45. Fornai M, Pellegrini C, Antonioli L, Segnani C, Ippolito C, Barocelli E, et al. Enteric dysfunctions in experimental Parkinson's disease: Alterations of excitatory cholinergic neurotransmission regulating colonic motility in rats. J Pharmacol Exp Ther 2016;356:434-44.

46. Singaram C, Ashraf W, Gaumnitz EA, Torbey C, Sengupta A, Pfeiffer R, et al. Dopaminergic defect of enteric nervous system in Parkinson's disease patients with chronic constipation. Lancet 1995;346:861-4.

47. Annerino DM, Arshad S, Taylor GM, Adler CH, Beach TG, Greene JG. Parkinson's disease is not associated with gastroin- 
testinal myenteric ganglion neuron loss. Acta Neuropathol 2012;124:665-80.

48. Corbille AG, Coron E, Neunlist M, Derkinderen P, Lebouvier T. Appraisal of the dopaminergic and noradrenergic innervation of the submucosal plexus in PD. J Parkinsons Dis 2014;4:571-6.

49. Devos D, Lebouvier T, Lardeux B, Biraud M, Rouaud T, Pouclet H, et al. Colonic inflammation in Parkinson's disease. Neurobiol Dis 2013;50:42-8.

50. Wakabayashi K. Where and how alpha-synuclein pathology spreads in Parkinson's disease. Neuropathology 2020;40:41525.

51. Hilton D, Stephens M, Kirk L, Edwards P, Potter R, Zajicek J, et al. Accumulation of alpha-synuclein in the bowel of patients in the pre-clinical phase of Parkinson's disease. Acta Neuropathol 2014;127:235-41.

52. Cersosimo MG. Gastrointestinal biopsies for the diagnosis of alpha-synuclein pathology in Parkinson's disease. Gastroenterol Res Pract 2015;2015:476041.

53. Corbille AG, Clairembault T, Coron E, Leclair-Visonneau L, Preterre C, Neunlist M, et al. What a gastrointestinal biopsy can tell us about Parkinson's disease? Neurogastroenterol Motil 2016;28:966-74.

54. Anderson G, Noorian AR, Taylor G, Anitha M, Bernhard D,
Srinivasan S, et al. Loss of enteric dopaminergic neurons and associated changes in colon motility in an MPTP mouse model of Parkinson's disease. Exp Neurol 2007;207:4-12.

55. Natale G, Kastsiushenka O, Fulceri F, Ruggieri S, Paparelli A, Fornai F. MPTP-induced parkinsonism extends to a subclass of TH-positive neurons in the gut. Brain Res 2010;1355:195-206.

56. Colucci M, Cervio M, Faniglione M, De Angelis S, Pajoro M, Levandis $\mathrm{G}$, et al. Intestinal dysmotility and enteric neurochemical changes in a Parkinson's disease rat model. Auton Neurosci 2012;169:77-86.

57. Tasselli M, Chaumette T, Paillusson S, Monnet Y, Lafoux A, Huchet-Cadiou C, et al. Effects of oral administration of rotenone on gastrointestinal functions in mice. Neurogastroenterol Motil 2013;25:e183-93.

58. Pellegrini C, Fornai M, Colucci R, Tirotta E, Blandini F, Levandis G, et al. Alteration of colonic excitatory tachykininergic motility and enteric inflammation following dopaminergic nigrostriatal neurodegeneration. J Neuroinflamm 2016;13: 146.

59. Benvenuti L, D'Antongiovanni V, Pellegrini C, Antonioli L, Bernardini N, Blandizzi C, et al. Enteric glia at the crossroads between intestinal immune system and epithelial barrier: Implications for Parkinson disease. Int J Mol Sci 2020; 21:9199.

Received for publication: 21 May 2021. Accepted for publication: 20 October 2021.

This work is licensed under a Creative Commons Attribution-NonCommercial 4.0 International License (CC BY-NC 4.0).

CCopyright: the Author(s), 2021

Licensee PAGEPress, Italy

European Journal of Histochemistry 2021; 65(s1):3278

doi:10.4081/ejh.2021.3278 